\title{
Strategi Digital Marketing X Wedding Organizer
}

\author{
Wina Rusdarina*, Tresna Wiwitan \\ Prodi Public Relation, Fakultas Ilmu Komunikasi, Universitas Islam \\ Bandung, Indonesia. \\ *Winarusdarina12@gmail.com, tresnawiwitan@yahoo.com
}

\begin{abstract}
The business development in the service sector is currently growing rapidly, especially in the wedding organizer industry. One of them is the X Wedding Organizer. The large number of wedding organizers that have sprung up has created intense competition. To face the tough competition, X Wedding Organizer conducted a marketing public relations strategy to achieve the company's goals. The objectives of the issues raised were (1) To find out the reasons why X chose the high-end market as the main target target (2) To find out and analyze X's publication method so that it was easily recognized in a short time (3) To find out and analyze the $\mathrm{X}$ branding method for get the right target. To reveal this problem, this study uses a type of qualitative research that is useful for providing facts and data about the $\mathrm{X}$ Wedding Organizer marketing public relations strategy. Then the data is analyzed using a case study approach that provides development on the research field under study. Then the data collection techniques used observation techniques, in-depth interviews with key informants, and documentation. While the theory used in this research is the excellent two-way symmetric model theory. The Result of the research of X Wedding Organizer marketing piblic relations strategy were determining the target market, $\mathrm{X}$ choosing the high-end market as the main target, then Rosric published using digital marketing and influencer marketing, after that $\mathrm{X}$ did branding through product branding to reach the target market.
\end{abstract}

Keywords: Marketing public relations, MPR strategy.

Abstrak. Perkembangan bisnis di bidang jasa saat ini semakin berkembang pesat, terutama pada industri wedding organizer. Salah satunya adalah X Wedding Organizer. Banyaknya wedding organizer yang bermunculan membuat adanya persaingan yang ketat. Untuk menghadapi persaingan yang ketat $\mathrm{X}$ Wedding Organizer melakukan strategi marketing public relations untuk mencapai tujuan perusahaan. Tujuan dari masalah yang diangkat yaitu untuk mengetahui (1) alasan mengapa X memilih market kelas atas sebagai taregt sasaran utama (2) menganalisis cara publikasi X agar mudah dikenal dalam waktu yang singkat (3) menganalisis cara branding X untuk mendapatkan target yang tepat sasaran. mengungkapkan persoalan tersebut penelitian ini menggunakan jenis penelitian kualitatif yang berguna memberikan fakta dan data mengenai strategi marketing public relations $\mathrm{X}$ Wedding Organizer kemudian data tersebut dianalisis menggunakan pendekatan studi kasus yang memberikan pengembangan terhadap bidang kajian yang diteliti. Kemudian teknik pengumpulan data menggunakan teknik observasi, wawancara secara mendalam kepada key informan, dan dokumentasi. Sedangkan teori yang digunakan dalam penelitian ini adalah teori excellent two-ways symmetric model. Hasil penelitian Strategi Marketing Public Relations X Wedding Organizer yaitu: menentukan target pasar, X memilih market kelas atas sebagai target utama, kemudian X melakukan publikasi menggunakan digital marketing dan influencer marketing, setelah itu X melakukan branding melalui product branding untuk mencapai target pasar yang dituju.

Kata Kunci: Marketing Public Relations, strategi MPR. 


\section{A. Pendahuluan}

Perkembangan usaha di bidang jasa saat ini sedang banyak mengalami peningkatan, khususny di Indonesia. Salah satunya adalah Wedding Organizer, terbukti dengan menjamurnya wedding organizer baik dalam skala kecil maupun skala besar di berbagai Kota.

Wedding Organizer (WO) adalah jasa untuk mengorganisasi acara pernikahan, baik dalam perencanaannya maupun saat hari pernikahan (Fithrati 2014:75). Wedding Organizer (WO) suatu usaha yang bergerak di bidang jasa, dengan kata lain perusahaan ini menjual jasa sebagai perancang acara pernikahan. Berbeda dengan Event Organizer (EO) yang merancang berbagai event baik formal maupun non-formal, Wedding Organizer (WO) lebih berfokus hanya pada acara pernikahan.

Menurut Badan Pusat Statistik (BPS) jumlah penduduk yang menikah terus bertambah setiap tahunnya. Di Jawa Barat, pada taun 2016 terdapat 59,40\% penduduk yang menikah di tahun 2017 meningkat menjadi 59,85\% dan di tahun 2018 lebih meningkat lagi menjadi 60,25\%.

Wedding Organizer menjadi tren saat ini, karena kesibukan masing-masing calon mempelai maka memilih wedding organizer adalah keputusan yang tepat. Hal ini membuktikan bahwa persaingan di dunia Wedding Organizer sangat ketat. Dengan begitu diperlukan adanya Strategi Marketing Public Relations untuk dapat tetap bertahan dalam menjalankan bisnis ini.

Keberadaan public relations dalam organisasi sangat penting. Public relations berperan sebagai komunikator organisasi dengan pihak lain serta organisasi dengan publiknya. Menjaga dan meningkatkan citra organisasi merupakan salah satu tugas dari seorang public relations. Public Relations bertanggung jawab untuk memberikan informasi, mendidik, meyakinkan, meraih simpati, dan membangkitkan ketertarikan masyarakat/publik untuk bisa menerima, mengerti dalam mempermudah pencapaian tujuan organisasi.

Peran strategi Marketing Public Relations sangat dibutuhkan dalam mempromosikan jasa wedding organizer baik melalui media, internet atau secara langsung sehingga dapat memperoleh klien. Menurut Effendy (2004:32) menjelaskan bahwa strategi komunikasi merupakan panduan perencanaan komunikasi (communication planning) dengan manajemen komunikasi (communication management) umtuk mrncapai tujuan yang telah ditetapkan.

Seiring berkembangnya zaman, perusahaan mulai memikirkan strategi lain untuk memasarkan produk atau jasa yang dimiliki salah satunya dengan menggunakan marketing public relations. Berbeda dengan marketing pada umumnya yang biasanya menggunakan iklan sebagai alat untuk memasarkan produk atau jasa, Marketing Public Relations menggunakan keterampilan berkomunikasi untuk menarik minat konsumen.

Marketing Public Relations penekanannya bukan pada selling (seperti pada periklanan) namun pada pemberian informasi, pendidikan dan upaya peningkatan pengertian lewat penambahan pengetahuan mengenai sebuah jasa, merk atau produk yang dimiliki perusahaan sehingga dampak yang diperoleh menjadi lebih kuat dan dapat lebih diingat oleh klien. Dengan tingkat komunikasi yang lebih intensif dan komunikatif, maka MPR merupakan sebuah konsep yang lebih tinggi daripada iklan biasa. MPR memberikan penekanan pada aspek manajemen dari marketing public relations dengan memperlihatkan kesejahteraan nasabah/klien. (Saka Abadi, 1994:46).

Oleh karena itu peran Marketing Public Relations merupakan panduan pelaksaan komunikasi dalam suatu perusahaan baik dalam perencanaan komunikasi (communication planning) maupun manajemen komunikasi (communication management) dalam mencapai suatu tujuan. Marketing Public Relations harus dapat mengelola perusahaan agar dapat terus bersaing dengan menggunakan strategi yang tepat. Oleh sebab itu, alasan penulis meneliti tentang MPR karena penulis mempunyai ketertarikan terhadap Marketing Public Relations yang sangat berperan dalam perkembangan perusahaan, selain itu penulis ingin mengetahui lebih dalam mengenai bagaimana proses perencaan, pelaksanaan dan evaluasi yang dilakukan untuk mendorong minat dan ketertarikan klien dengan melalui komunikasi informasi.

$X$ Wedding Organizer adalah sebuah wo yang ada di Kota Bandung tepatnya di Gg. Bapak Guru Atmawijaya Depan No 12, Sukamenak, Kec. Margahayu, Bandung, Jawa Barat, 40227 dan berdiri sejak tahun 2017. X Wedding Organizer tidak hanya melayani klien di Kota Bandung, $X$ juga melayani klien di daerah Jawa Barat dan Banten. Marketing PR yang dilakukan 
oleh X biasanya dilakukan melalui media sosial, yaitu instagram. Pengguna jasa WO biasanya kalangan anak muda yang sering menggunakan media sosial untuk mencari informasi, salah satu media sosial yang banyak digemari oleh anak muda adalah instagram dengan alasan inilah maka X memilih instagram untuk melakukan kegiatan marketing seperti penyampaian informasi mengenai jasa yang ditawarkan. Strategi marketing PR X ada pada content-content yang mereka upload di sosial media mereka, hal ini dilakukan untuk menarik minat klien dan memperoleh audiens enggagement.

Ada beberapa faktor yang membuat WO ini berkembang dengan pesat. Pertama, Sejak awal WO ini berfokus pada produk utama dan maintenance. Produk utama yang dimaksud adalah Sumber Daya Manusia (SDM) yaitu crew dan membuat pemahaman yang sama antara pihak manajemen dan semua crew. Target pasar WO ini sejak awal adalah melayani pasar untuk kelas B ke A, jadi dalam pemilihan crew WO ini merekrut orang-orang yang mempunyai potensi di bidang ini.

Kedua, $\mathrm{X}$ berfokus pada jasa yang mereka jual. WO ini tidak mempunyai kerjasama dengan vendor karena menurutnya akan sulit menyetarakan standar antara WO dan vendor. Dengan begitu, dalam pelaksanaannya mereka bisa lebih leluasa untuk mengkritik vendor. Ketiga, pemilihan positioning yang pas. Aldi sebagai Public Relations sangat unggul di bidang marketing dengan kemampuan komunikasi yang dimiliki Aldi bisa mengarahkan pembicaraan kepada klien. Kemudian, Agung sebagai manajer merupakan leader yang baik. Dan Aboy sebagai penanggung jawab di lapangan. Dan yang terakhir, adalah target pasar sejak awal X memilih target pasar grade A yang pada saat itu masih belum banyak WO yang memilih target pasar ini, dengan begitu strategi ini bisa mengurangi persaingan.

$\mathrm{X}$ sebagai wedding organizer mempunyai strategi marketing yang matang sejak awal sehingga WO ini dapat bertahan dan terus berkembang. $X$ mempunyai target pasarnya sendiri sehingga dalam kegiatan marketing WO ini memilih klien-klien yang sesuai dengan target pasar mereka. Saat kemunculannya $X$ langsung menangani beberapa event influencer dan seorang atlit pencak silat ternama di Kota Bandung. Dengan begitu, $X$ mulai dikenal sebagai salah satu wedding organizer yang berkelas. Tidak hanya itu, SDM yang mereka miliki yaitu crew tidak bisa sembarangan. Para crew merupakan orang-orang terpilih agar service yang mereka berikan kepada klien memperoleh hasil yang positif.

Alasan penulis memilih $X$ Wedding Organizer karena roatic mempunyai strategi marketing yang kuat dan merupakan salah satu wedding organizer ternama di Kota Bandung. Selain itu, $X$ juga mempunya strategi marketing yang unik dan menarik yaitu, klien akan diajak berdonasi dengan memilih $X$ sebagai wedding organizer. Penghasilan yang didapatkan $X$ akan disumbangkan $10 \%$ kepada pesantren untuk membantu biaya pembangunan, dan untuk mencukupi kebutuhan sehari-hari santri di pesantren tersebut. Dengan mayoritas masyarakat indonesia yang beragama Islam, maka strategi ini dapat membuat klien tertarik. Dengan memilih $X$ para klien ikut berdonasi untuk kepentingan pesantren. Berikut tabel perbedaan antara $X$ Wedding Organizer dengan WO lainnya.

Di era modern ini, dengan semakin tingginya angka persaingan antar WO maka diperlukan beberapa faktor pembeda antara $X$ Wedding Organizer dan WO lainnya. Beberapa perbedaan tersebut adalah (1) produk utama dan maintanancenya, SDM yang berkualitas. (2) Fokus pada jasa yang akan dijual, seperti yang telah dijelaskan $X$ hanya fokus pada pelayanan jasa. (3) Mempunyai target pasar yang jelas yaitu grade B ke A. (4) Kegiatan sosial, menyisihkan sebagian dari penghasilan yang diperoleh untuk pesantren.

Sesuai dengan pemaparan diatas, penulis merasa tertarik untuk melalukan penelitian lebih lanjut mengenai strategy marketing public relations yang dilakukan oleh $X$ Wedding Organizer. Dalam pelaksanaannya, pasti terdapat beberapa kendala yang dihadapi walaupun konsep yang dimiliki sudah matang, namun faktor kendala pasti selalu ada baik dalam skala kecil maupun skala besar. Untuk itu penulis ingin mengetahui lebih jauh mengenai faktor-faktor apa saja yang dihadapi dan bagaimana cara menanggulanginya. Setelah mengkaji lebih jauh mengenai strategi yang dilakukan penulis juga ingin mengetahui dampak atau hasil yang diperoleh dari strategi marketing yang telah dilakukan. Dengan demikian, penulis dapat menyimpulkan tingkat keberhasilan dan dapat memberikan evaluasi terhadap marketing yang 
telah dilakukan.

Berdasarkan latar belakang yang telah diuraikan, maka perumusan masalah dalam penelitian ini sebagai berikut: "bagaimana strategi digital marketing public relations $\mathrm{X}$ dalam mendapatkan target sasaran yang tepat dan dapat dikenal dalam waktu yang singkat ?". Selanjutnya, tujuan dalam penelitian ini diuraikan dalam pokok-pokok sbb.

1. Untuk mengetahui alasan $X$ memilih market kelas atas sebagai target sasaran utama.

2. Untuk mengetahui bagaimana cara publikasi $X$ agar mudah dikenal dalam waktu yang singkat.

3. Untuk mengetahui bagaimana cara branding $\mathrm{X}$ agar mendapatkan target sasaran yang tepat.

\section{B. Metodologi Penelitian}

Penelitian ini menggunakan metode kualitatif dalam upaya menelaah strategi marketing PR yang dilakukan X Wedding Organizer. Berusaha memahami, menginterpretasi, atau menafsirkan strategi yang dilakukan Humas X Wedding Organizer

Studi kasus (case study) yaitu pendekatan untuk mempelajari, menerangkan atau menginterpretasikan suatu kasus (case) dalam konteksnya secara natural tanpa adanya intervensi dari pihak luar (Yin, 2011). Peneliti melakukan analisis mengenai strategi marketing PR yang dilakukan $\mathrm{X}$ sehingga hasil penelitian dapat menemukan apakah strategi marketing PR yang digunakan dapat mencapai tujuan $\mathrm{X}$ dan bagaimana cara $\mathrm{X}$ mencapai tujuannya akan dibahas menggunakan teori perencanaan marketing PR.

Teknik pengumpulan data pada penelitian ini dilakukan dengan (1) indepth interview (wawancara mendalam) dengan CEO dan Founder X, Humas X, Crew X, dan pengguna jasa X Wedding Organizer. (2) Observasi, peneliti melakukan pengamatan mendalam terhadap kegiatan marketing PR yang dilakukan X Wedding Organizer dan ikut serta dalam beberapa kegiatan marketing PR yang dilakukan X Wedding Organizer. (3) Studi Pustaka, mengkaji buku, jurnal ilmiah dan artikel yang berkaitan dengan marketing PR.

\section{Hasil Penelitian dan Pembahasan}

Berdasarkan hasil observasi peneliti tahapan proses perencanaan marketing PR X adalah sebagai berikut: (1) menentukan target pasar, X memaparkan fakta dan data mengenai WO yang ada di Kota Bandung kemudian X menemukan fakta bahwa WO yang mempunyai target pasar utama kelas atas sangat sedikit, hal ini membuat peluang bagi $\mathrm{X}$ sehingga $\mathrm{X}$ menganalisis langkahlangkah apa yang harus diambil untuk membuat $\mathrm{X}$ bisa bersaing dengan WO kelas atas lainnya. (2) Membuat konten yang menarik, membuat konten iklan yang menarik untuk audiens. X memilih target pasar kelas atas sesuai dengan tujuan $\mathrm{X}$ dan membuat konten iklan yang relevan dengan target pasar yang dituju. Konten yang dibuat seperti konten pengenalan jasa yang $\mathrm{X}$ tawarkan dikemas melalui foto dan video dengan penyampaian pesan yang unik agar menarik minat audiens. Selain pembuatan konten, $\mathrm{X}$ juga merencanakan mengenai produk yang mereka tawarkan yaitu service dan Sumber Daya Manusia (SDM) yang akan dimaksimalkan dengan memberikan pemahaman kepada seluruh crew untuk melakukan service untuk market kelas atas. Beberapa contoh konten yang dibuat yaitu berupa pengenalan jasa $X$, hasil testimoni klien, dan kegiatan yang dilakukan perusahaan bisa dilihat di highlight dan feed instagram X, sedangkan untuk konten lain seperti Q\&A dan games biasanya hanya diposting melalui instagram story. Konten Q\&A dan games dibuat untuk menarik audiens enggagement. Sedangkan untuk konten pengenalan jasa, testimoni, dan kegiatan saat melakulan event dibuat agar audiens lebih mengenal X dan menumbuhkan tingkat kepercayaan audiens kepada X. Karena riset pasar sudah dilakukan, maka target pasar atau audiens sudah jelas seperti apa, maka konten iklan yang dibuat akan disesuaikan dengan target audiens yang dituju. (3) Publikasi, Pada tahap ini seluruh perencaan yang telah dibuat. Pada tahap ini X melaksanakan perencanaan yang telah dibuat sebelumnya. X membuat konten untuk dipublikasikan melalui sosial media Instagram. Saat pelaksanaan kegiatan Marketing PR X membangun komunikasi yang baik dengan klien mereka. $\mathrm{X}$ memaksimalkan cara kerja mereka dimulai dari hal terkecil hingga hal yang besar secara detail. Publikasi yang dilakukan $\mathrm{X}$ menggunakan 2 cara yaitu digital marketing dan influencer 
marketing. (4) Evaluasi feedback, Tujuan dari evaluasi ini adalah untuk mengetahui dan menganalisis apakah seluruh kegiatan PR sudah dilaksanakan sesuai dengan perencanaan dari hasil fakta dan data yang sudah dikumpulkan di lapangan. Pada tahap ini PR dapat mengetahui keberhasilan dari kegiatan PR yang telah dilakukan. Untuk mengetahui keberhasilan kegiatan marketing yang telah dilakukan, maka $\mathrm{X}$ melihat branding yang terbentuk dari audiens terhadap $\mathrm{X}$. Feedback yang diperoleh dari klien apakah positif atau negatif dan citra $\mathrm{X}$ di mata audiens seperti apa.

\section{Alasan X Memilih Market Kelas Atas}

Terdapat 2 alasan mengapa $\mathrm{X}$ memilih market kelas atas sebagai target sasaran utamanya. Yang pertama, mengurangi persaingan, Tingginya tingkat persaingan WO di Kota Bandung membuat $\mathrm{X}$ berfikir untuk membuat sebuah pemikiran baru. Pada saat itu, belum banyak WO yang secara khusus mentargetkan market kelas atas sebagai target pasar utama, maka X mengambil kesempatan itu untuk mengurangi persaingan. Yang kedua, mempunyai standart kualitas tinggi, $\mathrm{X}$ sejak awal sudah mempersiapkan seluruh pelayanan jasa yang akan diberikan dengan standart yang tinggi seperti crew, service yang diberikan, dan fasilitas. Karena itulah X memilih market kelas atas sesuai dengan pelayanan jasa yang diberikan.

\section{Publikasi yang dilakukan X agar Mudah Dikenal dalam Waktu Singkat}

1. Digital Marketing

Digital marketing adalah praktek marketing yang menggunakan saluran distribusi digital untuk mencapai konsumen dengan cara yang relevan, personal dan cost-effective (Satyo, 2009). Alasan $X$ menggunakan digital marketing sebagai salah satu strategi marketing PR yaitu karena digital marketing efektif digunakan dan relwvan dengan target pasar mereka. Digital marketing yang digunakan melalui Instagram, alasannya selain karena Instagram banyak digunakan generasi muda Instagram juga merupakan media yang memudahkan interaksi antara $\mathrm{X}$ dan audiens mereka.

2. Influencer Marketing

Influencer marketing yaitu melibatkan selebgram/influencer untuk kegiatan publikasi. Untuk melakukan digital marketing peran selebgram cukup penting untuk menjadi daya tarik audiens terhadap produk perusahaan. Alasan X menggunakan influencer sebagai salah satu strategi marketing PR yaitu karena taget pasar yang sudah ditentukan X sebelumnya, menunjukan bahwa target pasar mereka yaitu generasi muda dominan aktif di media sosial Instagram, selain itu, banyak juga target audiens yang mengikuti para influencers di instagram. $\mathrm{X}$ melakukan hal tersebut untuk meningkatkan pemahaman target audiens mengenai produk/jasa yang ditawarkan dan juga guna membuat aware audiens terkait produk/jasa yang dipromosikan oleh influencers agar mendorong perubahan perilaku audiens yang tadinya tidak mengetahui X, menjadi mengetahui dan memakai jasa X karena melihat promosi yang dilakukan oleh influencers yang diikutinya di sosial media Instagram.

X menerapkan Two-way Symmetrical Model (Model Simetris Dua Arah) dalam proses memasarkan produk mereka. Menurut Grunig dan Hunt. (dalam Prayudi, 2012 : 18), Praktisi public relations yang menggunakan model ini melakukan kegiatan PR berdasarkan riset dan menggunakan komunikasi untuk mengelola konflik dan meningkatkan pemahaman (understanding) dengan publik organisasi. Model ini menekankan pentingnya perubahan prilaku organisasi untuk merespon tuntutan publik. Sehingga praktisi public relations suatu organisasi selain berfungsi untuk membujuk publik, ia juga berusaha untuk mempersuasi pihak manajemen organisasi supaya memperhatikan apa yang menjadi keinginan publik. 


\section{Branding X Sebagai WO Kelas Atas}

1. Product Branding

Product branding memaksimalkan produk untuk memiliki nilai, kepribadian, identitas, dan posisi. Product branding memudahkan perusahaan untuk mengevaluasi kinerja dan nilai dari sebuah produk. Kesuksesan dapat dilihat dari produk itu sendiri apakah produk tersebut kompetitif dan mempunyai nilai di pasaran.

Menurut narasumber yang peneliti wawancarai X memilih product branding sebagai jenis branding yang dilakukan. Product branding adalah jenis branding yang menggunakan produk sebagai cara untuk memperoleh branding yang diinginkan perusahaan. Produk yang sukses adalah produk yang mampu mendorong audiens untuk memilih produknya daripada produk lain yang sejenis.

Produk yang dimiliki X yaitu service dan Sumber Daya Manusia (SDM). Untuk pelayanan (service) memiliki keunggulan dibandingkan WO lainnya. X juga selalu memberikan pelayanan yang baik baik sebelum, saat acara berlangsung, dan sesudah acara. Membangun hubungan yang baik dengan klien merupakan salah satu keunggulan X. Selain itu, SDM yang ada juga di perhatikan dengan baik. Kualifikasi SDM sesuai dengan pendidikan, pemahaman, dan cara berkomunikasi menjadi tolak ukur X dalam merekrut crew. Sejak awal crew diberikan pemahaman untuk melakukan service dengan untuk market $A$, dan crew juga harus mengenal dan mendalami produk X sehingga saat berhadapan dengan klien semua crew sudah siap.

Menurut Thomas (1991:48), mengatakan bahwa terdapat tiga pendekatan dalam MPR yang menggabungkan antara strategi pemasaran tradisional dan dimensi mega marketing yang membutuhkan komunikasi dengan bagian yang bukan bagian dari pemasaran tradisional. Adapun strategi-strategi tersebut yaitu push strategy, pull strategy, pass strategy. Dapat disimpulkan bahwa Pull Strategy harus mengembangkan kekuatan untuk menarik perhatian publik dengan cara menentukan strategi marketing PR yang tepat. Push Strategy memiliki kekuatan untuk mendorong pemasaran, X melakukan publikasi melalui digital marketing dan influencer marketing. Pass strategy memiliki kekuatan untuk mempengaruhi dan menciptaan opini publik yang positif, X membangun komunikasi yang baik dengan audiens untuk menbangun citra yang positif.X memilih target pasar kelas atas sebagai sasaran utama mereka, berbeda dengan penelitian sebelumnya yang hanya berfokus pada penambahan jumlah pengguna jasa secara signifikan, $\mathrm{X}$ memilih target pasar yang segmented sehingga kenaikan jumlah pengguna bukan menjadi fokus utama mereka. Kegiatan publikasi yang dilakukan X menggunakan digital marketing dan influencer marketing, berbeda dengan penelitian sebelumnya yang melakukan publikasi melalui event seperti workshop dan seminar. Cara publikasi yang dilakukan $\mathrm{X}$ lebih efektif dan efisien karena menghemat waktu dan biaya yang dikeluarkan, hasil dari publikasi yang dilakukan cukup baik tidak kalah dengan publikasi yang dilakukan melalui event. Selain itu X juga melakukan influencer marketing, cara ini sudah sering digunakan di kalangan WO kelas atas, namun belum digunakan di kalangan WO pada umumnya, dengan melakukan influencer marketing $\mathrm{X}$ dapat memperoleh klien yang sesuai dengan pasar mereka. X melakukan strategi marketing PR untuk mendapatkan branding yang sesuai dengan target pasar yang dutuju. Peran PR tidak hanya berfokus untuk memasarkan produk dan menambah jumlah pengguna jasa wedding organizer. Peran PR yang dilakukan X adalah membangun branding $\mathrm{X}$ sebagai WO kelas atas, dengan begitu peran PR yang dilakukan tidak hanya berfokus pada kenaikan jumlah pengguna jasa tetapi juga berfokus pada kualitas dan kredibelitas $X$ sebagai WO untuk selalu memberikan yang terbaik kepada setiap klien. X membangun komunikasi dua arah dengan audiens mereka melalui konten-konten yang dibuat melalui sosial media Instagram. Peran PR yang dilakukan X sesuai dengan teori excellence yang digunakan dalam penelitian ini dimana PR tidak hanya menjadi alat persuasif untuk menjual produk tapi PR juga harus membangun komunikasi dan baik dengan publiknya. 


\section{Kesimpulan}

Berdasarkan hasil penelitian dan pembahasan mengenai Strategi Marketing Public Relations X Wedding Organizer, dapat diambil kesimpulan sebagai berikut :

1. Strategi marketing PR yang dilakukan $X$ sejalan dengan proses operasional PR, $X$ menentukan target pasar, memaksimalkan produk (SDM dan service yang ditawarkan), publikasi, dan menjalin hubungan yang baik dengan audiens. Kegiatan Marketing PR yang dilakukan $\mathrm{X}$ merujuk pada target pasar yang sudah ditentukan sehingga kegiatan marketing yang dilakukan sejalan dengan target pasar yang ingin dituju.

2. Alasan $X$ memilih market kelas atas sebagai target sasaran utama karena 2 hal, yang pertama untuk mengurangi persaingan $X$ melihat peluang sedikitnya WO yang mempunyai target pasar kelas atas sehingga $\mathrm{X}$ memilih market kelas atas. Yang kedua, standar kualitas yang tinggi $\mathrm{X}$ memaksimalkan produk yang mereka miliki dimulai dari SDM (crew) dan service (pelayanan). Crew mempunyai standar kualitas tinggi untuk diberikan pemahaman mengenai pelayanan market kelas atas. Dengan pemahaman yang sama, pelayanan yang diberikan akan sesuai dengan yang diinginkan $\mathrm{X}$.

3. Publikasi $\mathrm{X}$ agar dikenal dalam waktu yang cepat adalah menggunakan digital marketing dengan media instagram, hal ini dilakukan karena prosea penyebaran informasi melalui sosial media sangat mudah dan cepat sehingga dapat menghemat waktu dan biaya. Selain itu, $\mathrm{X}$ juga menggunakan influencer marketing, yaitu menggunakan beberapa influencer/selebgram untuk mempromosikan produk mereka.

4. X memilih market kelas atas dan menyesuaikan pelayanan mereka untuk target pasar yang dituju, dengan begitu $\mathrm{X}$ dikenal dengan WO kelas atas. Hal ini diperoleh dari kegiatan strategi marketing PR yang telah dilakukan $\mathrm{X}$, dengan begitu branding $\mathrm{X}$ sebagai WO kelas atas cukup dikenal oleh audiens mereka.

\section{Acknowledge}

Penelitian ini dapat diselesaikan dengan bantuan dari beberapa pihak yanh telah membimbing, mendukung, dan menemani saya dalam proses pembuatan penelitian ini, saya ucapkan terimakasih kepada Allah SWT, kedua orang tua, dan juga kepada dosen pembimbing saya yaitu ibu Dr. Tresna Wiwitan Dra., M.Si yang telah membimbing saya dengan sangat baik sehingga saya dapat menyelesaikan penelitian ini.

\section{Daftar Pustaka}

[1] Harris, Thomas L. 2008. The Marketer's Guide To Public Relations, New York : JohnWiley \& Sons, Inc.,

[2] Harris, Thomas.L., \& Whalen, P.T.2006. The Marketers Guide To Public Relations in the 21th Century. Ohio : Thomson Higher Educations.

[3] Harris, L. Thomas. 1991. The Marketer's Guide To Public Relations (How today's Top Companies Using The New PR to Gain a Competitive Edge). John Wiley \& Sons, INC.USA

[4] Jurnal Managemen, Bahan Kuliah Manajemen. 2010. http://jurnal-sdm.blogspot.com/

[5] Kartajaya, Hermawan. 2006, December 23. Omzet tambah karena banting harga, bisnis tak akan lama. Koran Jawa Pos, hal. 8

[6] Kotler, Philip. 1993. Manajemen Pemasaran: Analisis, Perencanaan, Implementasi dan Pengendalian. Alih Bahasa Jaka Warsawa dan Herujati Purwoko. Jakarta: Erlangga.

[7] Kotler dan Keller. 2009. Manajemen Pemasaran. Jilid I. Edisi ke 13. Jakarta: Erlangga

[8] Ruslan, Rosady, SH. 2007. Manajemen Public Relations dan Media Komunikasi : Konsepsi \& Aplikasi, Jakarta : Raja Grafindo Persada.

[9] Satyo Fatwan. 2009. Intellectual Capital. Jakarta: Gramedia Pustaka Utama.

[10] Shimp, Terence, A. 2007. Periklanan, Promo, Aspek Tambahan Komunikasi Pemasaran Terpadu. Edisi Kelima. Jakarta : Airlangga. 
[11] Ruslan, Rosady. 2003. Manajemen Public Relations dan Media Komunikasi : Konsepsi dan Aplikasi, Jakarta : Raja Grafindo Persada.

[12] Sugiyono, 2017. Metode Penelitian Kuantitatif, Kualitatif, dan R\&D. Bandung: Alfabeta CV

[13] Wiwitan, Tresna, Neni Yulianita. 2017. Strategi 'Marketing Public Relations' Perguruan Tinggi Islam Swasta: Peluang dan Tantangan dii Era MEA https://ejournal.unisba.ac.id/index.php/mediator/article/download/2672/pdf Diakses Pada Tanggal 7 Desember Pkl 08.20 WiB

[14] Urban, Glen. L. 2004. Digital Marketing Strategy: text and cases. Pearson Education.

[15] Yin, Robert K. 2019. Studi Kasus: Desain dan Metode. Depok: PT Raja Grafindo Persada.

[16] Yulianita, Neny. 2005. Dasar-Dasar Public Relations. Pusat Penerbitan Universitas Islam Bandung 